\title{
Erratum to: Flavonoids activating adenosine monophosphate-activated protein kinase
}

Yeonjoong Yong ${ }^{1} \cdot$ Soon Young Shin $^{2}$ • Yearam Jung ${ }^{1} \cdot$ Hyeryoung Jung ${ }^{1}$ Seunghyun Ahn ${ }^{1}$ - Youhoon Chong ${ }^{1}$. Yoongho Lim $^{1}$

Published online: 29 December 2016

(C) The Korean Society for Applied Biological Chemistry 2016

Erratum to: J Korean Soc Appl Biol Chem (2015) 58(1):13-19

DOI 10.1007/s13765-015-0003-4

Regrettably, a statement for author contribution is missing in author list of the original version of the article (10.1007/ s13765-015-0003-4). The complete wording should be as follow: Yeonjoong Yong and Soon Young Shin contributed equally to this work.

Yeonjoong Yong and Soon Young Shin contributed equally to this work.

The online version of the original article can be found under doi:10.1007/s13765-015-0003-4.

Youhoon Chong

chongy@konkuk.ac.kr

$凶$ Yoongho Lim

yoongho@konkuk.ac.kr

1 Division of Bioscience and Biotechnology, BMIC, Konkuk University, Seoul 143-701, Korea

2 Department of Biological Sciences, Konkuk University, Seoul 143-701, Korea 